\title{
EFFECT OF THERMAL RECTIFICATION ON COLORS OF EUCALYPTUS SALIGNA AND PINUS CARIBAEA WOODS
}

\author{
Ana Lúcia Piedade Sodero Martins Pincelli", Luiz Fernando de Moura ${ }^{2}$, José Otávio Brito ${ }^{3}$
}

\begin{abstract}
Eucalyptus saligna and Pinus caribaea var. hondurensis woods underwent a variety of thermal rectification treatments (from $120^{\circ} \mathrm{C}$ to $180^{\circ} \mathrm{C}$ ) to evaluate the effect of heating on their colorimetric properties. The following color parameters were measured: lightness $(\mathrm{L}), \mathrm{a}^{\star}$ coordinate (green-red coordinate), $b^{\star}$ coordinate (blue-yellow coordinate), saturation $(\mathrm{C})$, and tonality angle $(\mathrm{H})$. This study demonstrates that thermal rectification can be regarded as a tool for adding value to wood through color modification by heating. Results also suggest that thermal rectification might be a tool for homogenizing wood tonality and reddish color between species. Both tested species have shown very distinct colorimetric behaviors as a function of thermal treatments. The conifer was more resistant to thermal darkening than the hardwood while exposed to temperatures below $160^{\circ} \mathrm{C}$. The green-red coordinate $\left(\mathrm{a}^{*}\right)$ and the tonality angle $(\mathrm{H})$ tended to be homogenized for both species, as they decreased in eucalyptus, and increased in pinus, as a function of heating. The effect of wood heating on the blue-yellow coordinate $\left(\mathrm{b}^{*}\right)$, saturation $(\mathrm{C})$, and tonality angle $(\mathrm{H})$ was likely to be opposite between both tested species.
\end{abstract}

Keywords: Eucalyptus, pinus, thermal treatment, color.

\section{INTRODUCTION}

Color is an important criterion to assess the quality of wood products. A precise description of color allows a better classification and valuation of final wood products. The simple visual assessment of color is, however, associated with personal impressions, resulting in a subjective evaluation. Therefore, accurate color evaluation should always involve the use of standard quantitative methods and equipments.

Some systems for quantitative description of colors were created after the 1930's, to complement the chromaticity diagram proposed by the International Commission on Illumination (CIE). Among them, the CIELAB (or CIE L $\mathrm{a}^{*} \mathrm{~b}^{\star}$ ) color space, created in 1976, is recommended by the CIE, for wood color measurements. The CIELAB color space quantifies colors based on the parameters presented in figure 1 (Hunter 1975).

$\mathrm{L}$ indicates lightness and varies from 0 (pure black) to 100 (pure white) is a scale also called "gray axis". $\mathrm{a}^{\star}$ and $\mathrm{b}^{*}$ are the chromatic coordinates, located in axis perpendicular to the gray axis. $a^{\star}$ identifies the color in the green-red axis. When $a^{*}$ is positive, it is located in the red portion of the axis; when $\mathrm{a}^{*}$ is negative, it is found in the green side of the axis. $\mathrm{b}^{\star}$ describes the blue-yellow component of the color. When $b^{*}$ is positive, the color is located in the yellow side of the axis; when

\footnotetext{
${ }^{1}$ Ph.D. Student. Departamento de Ciências Florestais, E.S.A. "Luiz de Queiroz", Universidade de São Paulo (ESALQ/USP), Laboratórios Integrados de Química, Celulose e Energia (LQCE), Piracicaba, São Paulo, Brazil.

${ }^{2}$ Ph.D. Associate Researcher. Departamento de Ciências Florestais, E.S.A. "Luiz de Queiroz", Universidade de São Paulo (ESALQ/USP), Laboratórios Integrados de Química, Celulose e Energia (LQCE), Piracicaba, São Paulo, Brazil.

${ }^{3}$ Ph.D. Professor. Departamento de Ciências Florestais, E.S.A. "Luiz de Queiroz", Universidade de São Paulo (ESALQ/USP), Laboratórios Integrados de Química, Celulose e Energia (LQCE), Piracicaba, São Paulo, Brazil.

Corresponding author: •analucia.sodero@hotmail.com

Received: 18.10.2011 Accepted: 25.03.2012
} 
$\mathrm{b}^{\star}$ is negative, the color tends to blue. $\mathrm{C}$ describes color saturation, which represents the distance from the lightness axis (gray axis). The greater the distance from the gray axis, the more saturated (or vivid, pure) is the color.

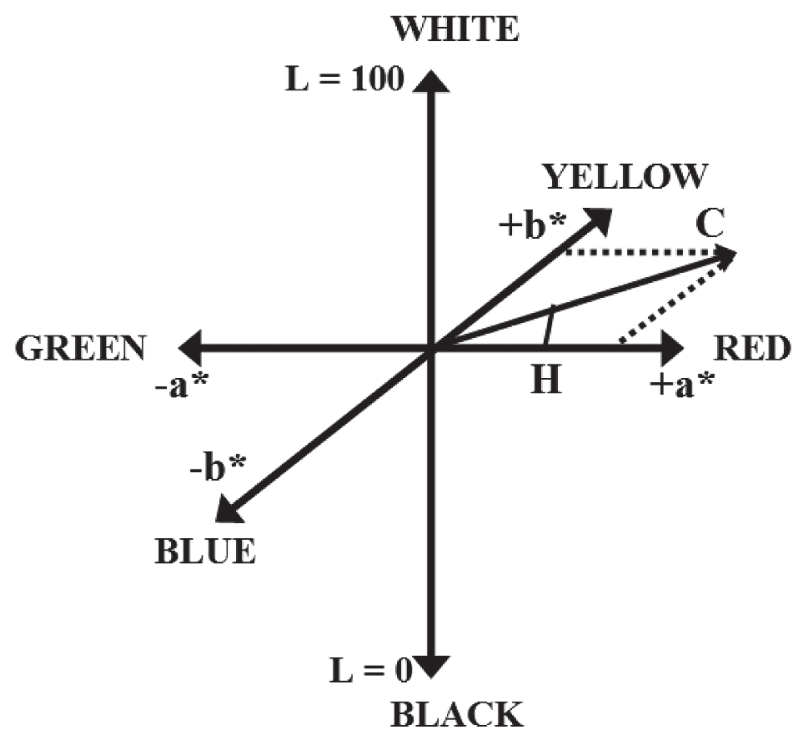

Figure 1. CIELAB (1976).

$\mathrm{H}$ represents the hue angle or tonality angle on the chromatic circle whose value has origin in the green-red axis, counting positively in the trigonometric sense of rotation. This angle indicates the dominance of a tonality component in a color.

Color measurement can be performed by using colorimeters or spectrophotometers. According to Michot (1994), colorimeters are equipped with a series of filters (blue, yellow, green, red) and photo-detectors, which attempt to reconstitute the response of an observer exposed to a given color. Spectrophotometers, in turn, measure the reflectance of a sample compared with standard-white exposed to the same wavelength, which results in a percentage of light reflected by the sample compared to a white standard.

Changes in wood color can be caused by multiple external factors that affect structural chemical components and extractives of wood (Hon 1975). Among these factors, the literature mentions ultraviolet radiations, which cause deterioration of wood chemical components, mainly the lignin (Rowell 1990); oxidation and condensation of some chemical components (e.g. poly-phenols and extractives) (Webb \& Sullivan 1964); the $\mathrm{pH}$ and moisture content of soil (Nelson et al. 1969); type of soil (Flot 1988); geographic location (Sullivan 1967); content of extractives (Hiller et al. 1972); the age of trees (Klumpers et al. 1993) etc. The interaction of wood color with all of these factors will also depend on the location of boards in the tree: different color behaviors are reported as a function of the pit-to-bark direction, as well as tree height (Flot 1988), and cutting plan (transversal, tangential or radial) (Beckwith 1979, Hofmann 1987).

Several studies corroborate the reduction of wood lightness as a function of heating (Luro 1997, Bekhta and Niemz 2003, Johansson and Morén 2006, de Moura and Brito 2011). Bourgois et al. (1991) explains that wood darkening during heating might be related to a reduction in holocellulose content as the temperature increases. 
Previous research has indicated that the red component of wood color might provide quite different responses to heating, as a function of species studied. De Moura and Brito (2011) report that the level of red color in Eucalyptus grandis decreased abruptly with increasing temperatures. However, Johansson and Morén (2006) demonstrated an increment of red color in birch wood after a thermal treatment, compared with non-treated samples.

In its original chemical composition, wood has quinonoids and stilbene structures in lignin, as well as organoleptic compounds in extractives, which confer part of its yellow color (Falkehag et al. 1966). These compounds might be changed at high temperatures. Bekhta and Niemz (2003) report a sensible reduction of yellow color in Picea abies after treatment at temperatures above $150^{\circ} \mathrm{C}$. Similarly, de Moura and Brito (2011) found a severe decrease of yellow color in samples of Pinus caribaea var. hondurensis after thermal rectification above $160^{\circ} \mathrm{C}$.

This study aims to evaluate the effect of thermal treatment (thermal rectification) on colorimetric properties of Eucalyptus saligna and Pinus caribaea var. hondurensis woods. These species present relatively fast growing rates and low market values, in comparison to commercial tropical woods. Both species are very representative of silvicultural activity in Brazil. It is recognized that thermal rectified eucalyptus and pinus woods acquire colors similar to those observed in tropical woods. This might be an important factor to add value to these relatively low-valuated woods by means of thermal treatments.

\section{MATERIAL AND METHODS}

\section{Material}

Eucalyptus saligna (25-years old) and Pinus caribaea var. hondurensis (20-years old) boards were directly obtained from operating sawmills of companies Duratex S/A (municipality of Agudos, State of São Paulo) and Eucatex S/A Indústria e Comércio (municipality of Itatinga, State of São Paulo), respectively. Boards were machined to $400-\mathrm{cm}(\mathrm{L})$ length, $18-\mathrm{cm}(\mathrm{T})$ width, and $3-\mathrm{cm}(\mathrm{R})$ thickness. Given that boards were predominantly originated from heartwood, the proportion of sapwood has not been previously quantified.

\section{Preparation of samples for thermal rectifications}

Boards were air-dried during 4 months under protection against weathering agents, until reaching moisture contents between 10 and $15 \%$. Afterwards, boards were cut into samples of $70-\mathrm{cm}$ (L) length, $18-\mathrm{cm}(\mathrm{T})$ width, and $3-\mathrm{cm}(\mathrm{R})$ thickness. A pre-selection was performed to eliminate samples with defects (cracks, knots, bending etc.). A portion of samples was kept in their natural state as control samples, and another portion underwent thermal rectifications.

Prior to thermal rectifications, samples were dried in an electrical resistance oven, equipped with a system for air circulation, at $100^{\circ} \mathrm{C}$, until reaching constant weight. This previous drying procedure attempted to eliminate the effect of wood moisture on thermal rectification process.

\section{Thermal rectifications}

Thermal rectifications were performed in the LQCE (Laboratórios Integrados de Química, Celulose e Energia - Integrated Laboratories of Chemistry, Pulp and Energy) of the Department of Forest Sciences at ESALQ/USP (Escola Superior de Agricultura "Luiz de Queiroz", University of São Paulo). Wood samples were heat treated in an electrical resistance oven, equipped with a system for air circulation (FANEM Mod. 320 Digital), with a nominal chamber volume of $0.45 \mathrm{~m}^{3}$. 
A rate of heating of $0.033^{\circ} \mathrm{C} /$ minute was applied, with final temperatures of $120^{\circ} \mathrm{C}, 140^{\circ} \mathrm{C}, 160^{\circ} \mathrm{C}$, and $180^{\circ} \mathrm{C}$. Maximum temperatures limited to $180^{\circ} \mathrm{C}$, combined with a mild rate of heating, were chosen to induce color changes without causing considerable mass loss or physical and chemical changes in wood.

At the start of thermal rectification program, samples were placed into the oven with an initial temperature of $100^{\circ} \mathrm{C}$. After heat treatment, samples were kept inside the oven to cool, until reaching $30^{\circ} \mathrm{C}$.

\section{Preparation of samples for color measurements}

Color assessments were performed in the LPF (Laboratório de Produtos Florestais; Laboratory of Forest Products; Brasília-DF). For each thermally-rectified board, three random samples were machined to $18-\mathrm{cm}(\mathrm{L})$ length, $5-\mathrm{cm}(\mathrm{T})$ width, and 3-cm (R) thickness. Samples were then manually sanded with 120-grit sandpaper and stored in absence of light to prevent photo-oxidation of surfaces.

\section{Color measurements}

For color measurements, a Datacolor Microflash 200d spectrophotometer was used. Measurements were undertaken using the D65 standard illuminant (daylight simulator) and a $10^{\circ}$ angle of observation. For each wood sample, a sequence of ten repetitions of color measurements has been taken from distinct locations on the surface.

The following color parameters were measured: lightness (L), $\mathrm{a}^{\star}$ coordinate (green-red coordinate), $\mathrm{b}^{\star}$ coordinate (blue-yellow coordinate), saturation $(\mathrm{C})$, and tonality angle $(\mathrm{H})$. These parameters were measured according to the CIELAB (1976) color space, as shown in Figure 1. The values of saturation $(\mathrm{C})$ and tonality angle $(\mathrm{H})$ were calculated by means of the following equations:

$$
\begin{gathered}
C=\sqrt{\left(a^{*}\right)^{2}+\left(b^{*}\right)^{2}} \\
H=\arctan \left(\frac{b^{*}}{a^{*}}\right)
\end{gathered}
$$

\section{Statistical analysis}

Color parameters were expressed as an average of 30 measurements per treatment. Multiple comparisons among means were performed by using Tukey's tests at $5 \%$ significance level.

\section{RESULTS AND DISCUSSION}

The results of color measurements for lightness (L), green-red coordinate $\left(\mathrm{a}^{\star}\right)$, blue-yellow coordinate $\left(b^{\star}\right)$, saturation $(\mathrm{C})$, and tonality angle $(\mathrm{H})$, as well as multiple comparisons among means of these parameters for different maximum temperatures in thermal rectification (Tukey's test at 5\% significance level) tested on Eucalyptus saligna and Pinus caribaea var. hondurensis woods, are compiled in figures 2 to 6 .

Even after thermal treatments, pinus wood kept lighter colors (66.5) than the hardwood (53.9, thermal treatments pooled). For both species, the lightness index (L) was significantly reduced as a 
result of thermal rectification. For eucalyptus, the decrease in lightness was more noticeable from $120^{\circ} \mathrm{C}$ to $140^{\circ} \mathrm{C}$ and from $160^{\circ} \mathrm{C}$ to $180^{\circ} \mathrm{C}$ (Figure 2). For pinus, in turn, samples started to significantly darken only above $140^{\circ} \mathrm{C}$, and the most abrupt reduction of lightness was observed from $160^{\circ} \mathrm{C}$ to $180^{\circ} \mathrm{C}$ (Figure 2). These results indicate that the conifer was more resistant to thermal darkening than the hardwood while exposed to temperatures below $160^{\circ} \mathrm{C}$. For temperatures above $160^{\circ} \mathrm{C}$, however, pinus is likely to undergo some important chemical changes that cause fast darkening. The reasons for wood darkening caused by heating have been widely reported by several authors (Luro 1997, Bekhta and Niemz 2003, Johansson and Morén 2006, de Moura and Brito 2011).

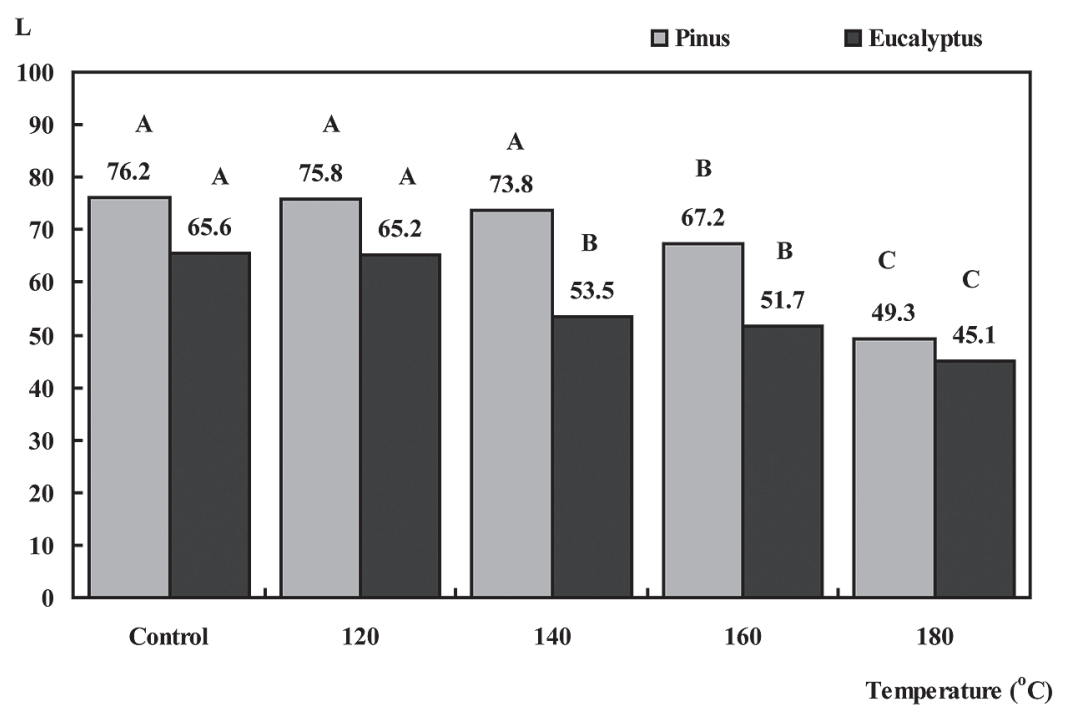

Figure 2. Lightness index (L) obtained for E. saligna and P. caribaea var. hondurensis woods after thermal rectification at different maximum temperatures. Letters (A, B, and $\mathrm{C})$ are for comparisons among means, for each species separately: means followed by the same letter are not significantly different at the $5 \%$ probability level (Tukey's multiple comparison tests).

For the green-red coordinate $\left(\mathrm{a}^{*}\right)$, wood heating caused very distinct behaviors between both species studied. For heating below $160^{\circ} \mathrm{C}$, eucalyptus kept higher levels of red color (12.4 in average) than pinus (6.9 in average, for control, $120^{\circ} \mathrm{C}$, and $140^{\circ} \mathrm{C}$ pooled). As the temperature increased, however, $\mathrm{a}^{*}$ tended to be homogenized for both species (Figure 3 ). Eucalyptus tended to become less reddish as the maximum temperature in thermal rectification increased. However, this reduction in $\mathrm{a}^{\star}$ was only significantly noticed from $140^{\circ} \mathrm{C}$ to $160^{\circ} \mathrm{C}$. The reduction of $\mathrm{a}^{*}$ with heating had also been reported by de Moura and Brito (2011) for Eucalyptus grandis wood. It is assumed that this reduction in red color is associated with volatilizing of some chemical compounds that confer red color to eucalyptus (probably phenolic extractives), as wood is heated.

Oppositely, pinus became gradually more reddish as the maximum temperature in thermal treatment increased (Figure 3), and reached higher levels of $\mathrm{a}^{*}$ than those observed in eucalyptus when heating at $180^{\circ} \mathrm{C}$. In a previous work, de Moura and Brito (2011) could not statistically detect changes in $\mathrm{a}^{\star}$ for pinus wood as a function of heating. However, the authors confirm that pinus acquired higher levels of red color than eucalyptus for thermal rectifications above $160^{\circ} \mathrm{C}$. 


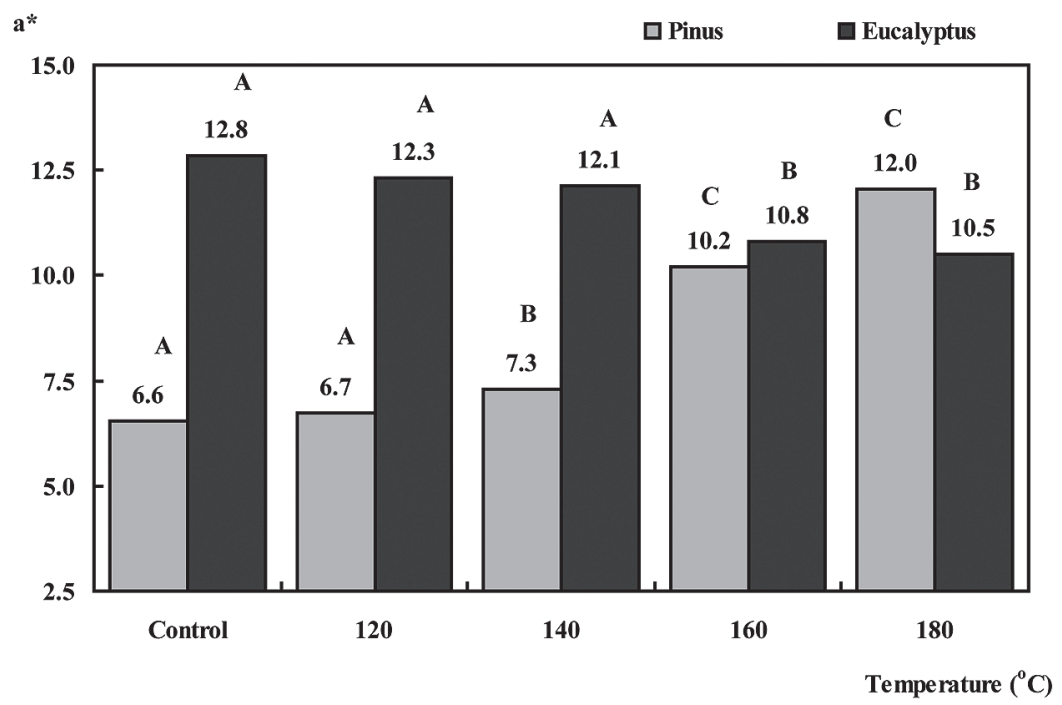

Figure 3. Green-red coordinate $\left(\mathrm{a}^{*}\right)$ obtained for E. saligna and P. caribaea var. hondurensis woods after thermal rectification at different maximum temperatures. Letters (A, B, and C) are for comparisons among means, for each species separately: means followed by the same letter are not significantly different at the $5 \%$ probability level (Tukey's multiple comparison tests).

The maximum temperatures of treatment caused very distinct behaviors of the blue-yellow coordinate $\left(b^{*}\right)$ for both species. In general, pinus wood conserved higher levels of yellow (26.5) than those observed in eucalyptus wood (17.4, thermal treatments pooled). For the range of maximum temperatures tested, the effect of wood heating on $b^{*}$ is likely to be quadratic for both species; however, changes in $b^{\star}$ as a function of temperature seem to be opposite between tested species (Figure 4).

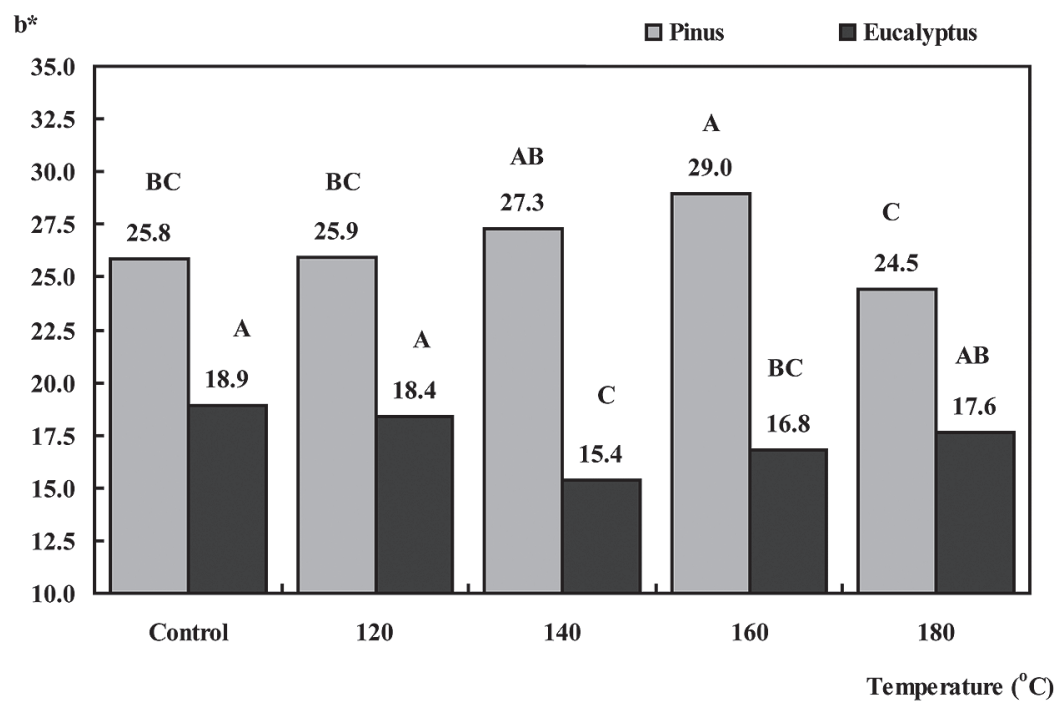

Figure 4. Blue-yellow coordinate $\left(\mathrm{b}^{\star}\right)$ obtained for E. saligna and P. caribaea var. hondurensis woods after thermal rectification at different maximum temperatures. Letters (A, B, and C) are for comparisons among means, for each species separately: means followed by the same letter are not significantly different at the $5 \%$ probability level (Tukey's multiple comparison tests). 
For eucalyptus, $\mathrm{b}^{\star}$ was decreased by heating until $140^{\circ} \mathrm{C}$; above $140^{\circ} \mathrm{C}$, eucalyptus turned to gradually recover yellow color. Pinus wood, oppositely to the hardwood, gained its maximum level of yellow color with heating until $160^{\circ} \mathrm{C}$, and presented reduction of $\mathrm{b}^{*}$ from $160^{\circ} \mathrm{C}$ to $180^{\circ} \mathrm{C}$. The work by de Moura and Brito (2011) corroborates the reduction of $\mathrm{b}^{*}$ in pinus for thermal rectification above $160^{\circ} \mathrm{C}$. In a study with thermally-treated Picea abies, Bekhta and Niemz (2003) report a considerable decrease in yellow color after treatments above $150^{\circ} \mathrm{C}$. This result suggests that considerable chemical changes, involving volatilizing of some compounds (probably extractives) that confer yellow color to pinus wood, might have occurred in treatments above $160^{\circ} \mathrm{C}$.

The yellow color is associated with the presence of chromophores in the lignin and extractives, as well as organometallic compounds in extractives. Untreated wood has quinonoids and stilbene structures in its lignin, which confer part of its yellow color (Falkehag et al. 1966). It is believed that thermal rectification has caused changes, to some extent, in the structure and/or quantity of these wood compounds.

For all conditions tested, color saturation (C) was greater in the conifer than in the hardwood. For pinus, the maximum value of $\mathrm{C}$ was obtained through thermal rectification at $160^{\circ} \mathrm{C}$. Eucalyptus, in turn, underwent a decrease in $\mathrm{C}$ from $120^{\circ} \mathrm{C}$ to $140^{\circ} \mathrm{C}$, with no significant effect as a function of further heating (Figure 5). Given that $\mathrm{C}$ is calculated as a function of $\mathrm{a}^{\star}$ and $\mathrm{b}^{\star}$ coordinates, and that $b^{*}$ is usually higher than $\mathrm{a}^{*}$ when measured on wood, it is expected that $\mathrm{b}^{*}$ has a greater influence on actual values of $C$. This explains why the pattern of variation of $C$ is clearly similar and dependent to that observed in the yellow color (Figures 4 and 5).

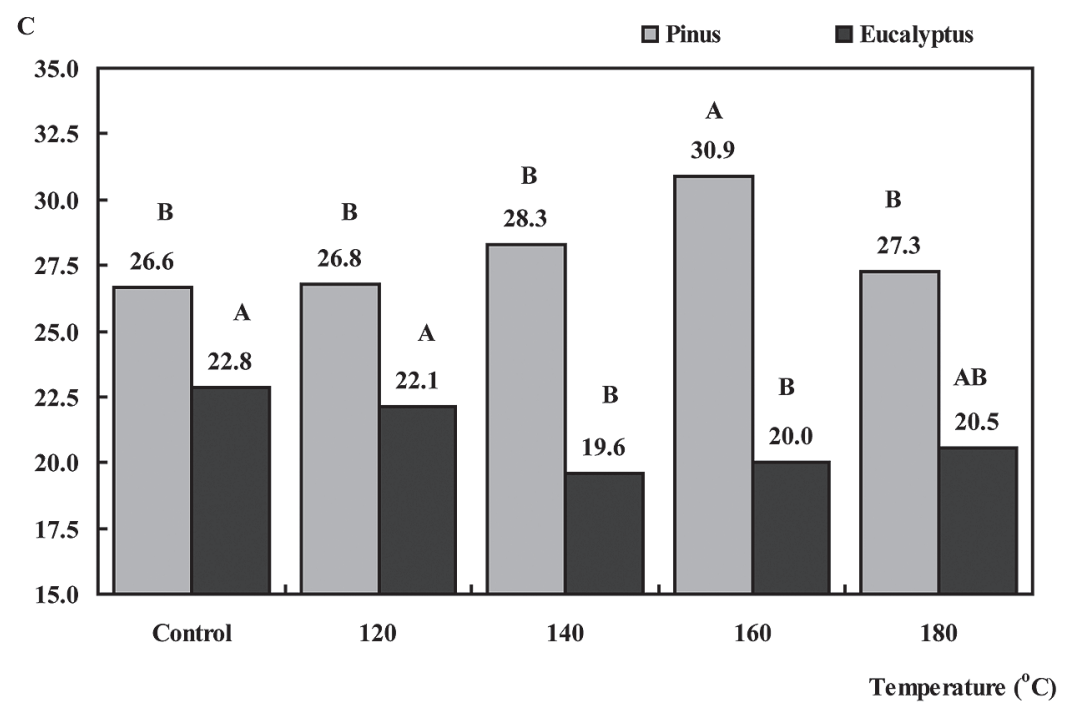

Figure 5. Color saturation (C) obtained for E. saligna and P. caribaea var. hondurensis woods after thermal rectification at different maximum temperatures. Letters (A and B) are for comparisons among means, for each species separately: means followed by the same letter are not significantly different at the $5 \%$ probability level (Tukey's multiple comparison tests).

Regarding the tonality angle $(\mathrm{H})$, both species revealed quite opposite behaviors due to heating: although pinus wood provided higher $\mathrm{H}$ values than eucalyptus wood, the tonality parameter seemed to be homogenized by means of heating. As observed in figure 6, the tonality angle was sensibly reduced by heating pinus wood, while it was increased in eucalyptus. This pattern of variation caused a reduction of the differences of tonality between both species, as the temperature increased. This 
result suggests that thermal rectification might be a tool for homogenizing wood tonality.

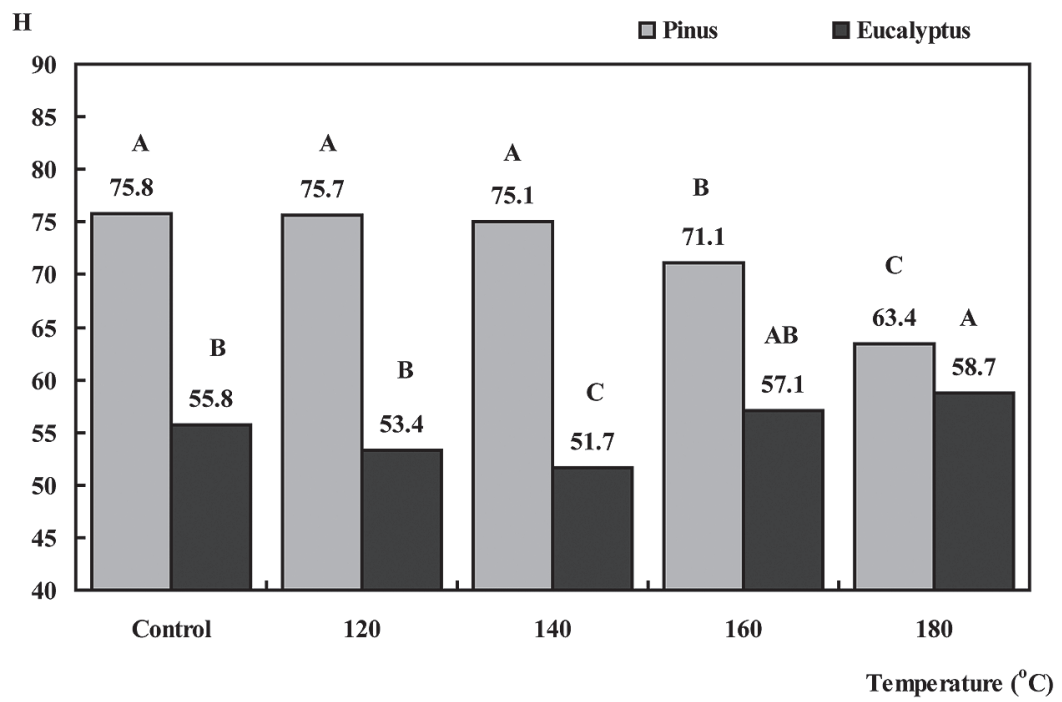

Figure 6. Tonality angle $(\mathrm{H})$ obtained for E. saligna and P. caribaea var. hondurensis woods after thermal rectification at different maximum temperatures. Letters $(\mathrm{A}, \mathrm{B}$, and $\mathrm{C})$ are for comparisons among means, for each species separately: means followed by the same letter are not significantly different at the $5 \%$ probability level (Tukey's multiple comparison tests).

The results of this study confirm that thermal rectification can be a tool for modification of wood color. In this context, two possibilities can be proposed: the first, is the adoption of thermal rectification as a tool for adding value to wood by modifying its colors, according to actual market preferences; the second, is the use of colorimetric measurements as a tool for controlling thermal treatments, as previously mentioned by Machinery Business Society (1997) and Luro (1997).

\section{CONCLUSIONS}

Thermal rectification can be regarded as a tool for adding value to wood through color modification by heating. In this study, Eucalyptus saligna and Pinus caribaea var. hondurensis have shown very distinct colorimetric behaviors as a function of thermal treatments.

The conifer was more resistant to thermal darkening than the hardwood while exposed to temperatures below $160^{\circ} \mathrm{C}$.

The green-red coordinate $\left(\mathrm{a}^{*}\right)$ tended to be homogenized for both species, as it decreased in eucalyptus, and increased in pinus, as the maximum temperature in thermal treatment increased.

The effect of wood heating on the blue-yellow coordinate $\left(b^{*}\right)$ is likely to be quadratic for both species; however, changes in $b^{\star}$ as a function of temperature seem to be opposite between tested species.

For pinus, the maximum value of saturation $(\mathrm{C})$ was obtained through thermal rectification at $160^{\circ} \mathrm{C}$. Eucalyptus, in turn, underwent a decrease in $\mathrm{C}$ from $120^{\circ} \mathrm{C}$ to $140^{\circ} \mathrm{C}$, with no significant effect as a function of further heating. 
The tonality angle $(\mathrm{H})$ was sensibly reduced by heating pinus wood, while it was increased in eucalyptus. This pattern of variation caused a reduction of the differences of tonality between both species, as the temperature increased. This result suggests that thermal rectification might be a tool for homogenizing wood tonality.

\section{REFERENCES}

Beckwith, J.R.III. 1979. Theory and Practice of Hardwood Color Measurement. Wood Science 11(3): 169-175.

Bekhta, P.; Niemz, P. 2003. Effect of High Temperature on the Change in Color, Dimensional Stability and Mechanical Properties of Spruce Wood. Holzforschung 57(5): 539-546.

Bourgois, P.J.; Janin, G; Guyonnet, R. 1991. La mesure de couleur: Une méthode détude et d’optimisation des transformations chimiques du bois thermolysé. Holzforschung 45(5): 377-382.

de Moura, L.F.; Brito, J.O. 2011. Effect of thermal rectification on colorimetric properties of Eucalyptus grandis and Pinus caribaea var. hondurensis woods. Scientia Forestalis 39(89):69-76.

Falkehag, S.I.; Marton, J.; Adler, E. 1966. Chromophores in Kraft lignin. In: Lignin Structure and Reactions. Ed. Marton, J. Am. Chem. Soc : Washington D. C., EUA, pp.75-89.

Flot, J.L. 1988. La couleur du Chêne de tranchage français. Méthodologie de la mesure, variabilité géographique, classement industriel et incidences économiques. Mémoire de $3^{\text {ème }}$ année E.N.I.T.E.F., Station de Recherches sur la Qualité des Bois, INRA-CRF, Nancy-Champenoux, 89p.

Hiller, C.H.; Freese, F.; Smith, D.M. 1972. Relationships in black walnut heardwood between color and other physical and anatomical characteristics. Wood and Fiber 4(1): 38-42.

Hofmann, P. 1987. Mesure de la variabilité de la couleur du bois: méthodologie et influences de l'anatomie du plan ligneux et des variations angulaires du débit. D.E.A. «Sciences du Bois», Université de Nancy I, Station de Recherches sur la Qualité des Bois, INRA-CRF, Nancy-Champenoux, Octobre, $74 \mathrm{p}$.

Hon, N.S. 1975. Formation of free radicals in photoirradiated cellulose. VI. Effect of lignin. Journal of Polymer Science: Polymer Chemistry Edition 13: 2641-2652.

Hunter, R.S. 1975. The measurement of appearance. New York: John Wiley and Sons. 391p.

Johansson, D.; Morén, T. 2006. The potential of colour measurement for strength prediction of thermally treated wood. Holz als Roh- und Werkstoff 64(2): 104-110.

Klumpers, J.; Janin, G.; Becker, M. 1993. The influences of age, extractive content and soil water on wood color in oak: the possible genetic determination of wood color. Annales des Sciences forestières 50(1): 403-409.

Luro, D. 1997. Traitement thermique du bois: l'aboutissement de dix ans de recherche. Le Bois National. CTBA (Centre technique du bois et de l'ameublement), Paris, France. pp. 12-15.

Machinery Business Society. 1997. Les nouveaux matériaux. Machinery Business Society, Saint Clair Du Rhone, France, 23p. 
Michot, S. 1994. Classification subjective des parquets de chêne: rapport de stage. Epinal: Université de Nancy I, 48 pp.

Nelson, N.D.; Maeglin, R.R.; Wahlgren, H.E. 1969. Relationship of black walnut wood color to soil properties and site. Wood Fiber 1: 29-37.

Rowell, R.M. 1990. Chemical modification of wood: its application to composite products. FRI Bulletin 153:57-67.

Sullivan, J.D. 1967. Color characterization of wood: color parameters of individual species. Forest Products Journal 17(8): 25-29.

Webb, D.A.; Sullivan, J.D. 1964. Surface effect of light and water on wood. Forest Products Journal 14(11): 531-534. 